\title{
Far-field lithospheric deformation in Tibet during continental collision
}

\author{
Katherine E. Dayem, ${ }^{1}$ Peter Molnar, ${ }^{1}$ Marin K. Clark, ${ }^{2}$ and Gregory A. Houseman ${ }^{3}$ \\ Received 16 June 2008; revised 12 January 2009; accepted 18 August 2009; published 3 December 2009.
}

[1] Crustal deformation along the present-day northern margin of the Tibetan Plateau has occurred since mid to late Eocene time, soon after India collided with Eurasia. Assuming that on these distance and time scales the lithosphere can be approximated using a thin viscous sheet, we show that far-field lithospheric deformation caused by an indenting boundary is expected to start shortly after collision begins. When a strong region analogous to cratonic lithosphere like that of the Tarim Basin is included in the calculations, shear and vertical strain rates concentrate along the southern edge of the strong region, resulting in enhanced deformation there. In calculations scaled to the dimensions of India and the Tibetan Plateau, shear and vertical strain rates on the northern edge of the plateau increase soon after collision begins. Crustal thickening accelerates later in the calculations. We propose that the apparent increased exhumation (and perhaps surface uplift) around $10 \mathrm{Ma}$ may signal the arrival of the thickening front. Citation: Dayem, K. E., P. Molnar, M. K. Clark, and G. A. Houseman (2009), Far-field lithospheric deformation in Tibet during continental collision, Tectonics, 28, TC6005, doi:10.1029/2008TC002344.

\section{Introduction}

[2] Convergence between the Indian and Asian continents, following their collision at $\sim 45-55 \mathrm{Ma}$ [e.g., Garzanti and Van Haver, 1988; Rowley, 1996, 1998; Searle et al., 1987; Zhu et al., 2005], is accommodated at least in part by deformation of the Tibetan Plateau lithosphere. Views of how the lithosphere accommodates this deformation, however, appear to conflict with the timing of strain inferred from geologic dating.

[3] Two main frameworks to explain deformation of Tibetan lithosphere have been developed. In the first, strain is accommodated by slip on large-scale strike-slip faults separating essentially rigid blocks of lithosphere [e.g., Avouac and Tapponnier, 1993; Replumaz and Tapponnier,

\footnotetext{
${ }^{1}$ Department of Geological Sciences, University of Colorado, Boulder, Colorado, USA.

${ }^{2}$ Department of Geological Sciences, University of Michigan, Ann Arbor, Michigan, USA.

${ }^{3}$ School of Earth and Environment, University of Leeds, Leeds, UK.

Copyright 2009 by the American Geophysical Union. 0278-7407/09/2008TC002344
}

2003; Tapponnier et al., 1982, 1986, 2001]. As India moves north toward stable Asia, convergence is accommodated by slip on successively activated thrust and strike-slip faults, such that the plateau grows northward in distinct steps [Tapponnier et al., 2001]. In the second, the lithosphere deforms as a continuous viscous fluid so that convergence is accommodated either by flow within the middle and lower crust [e.g., Clark and Royden, 2000; Royden, 1996] or across the entire lithosphere [e.g., England and Houseman, 1986; England and McKenzie, 1982; Molnar and Tapponnier, 1975; Tapponnier and Molnar, 1976]. In the case of a homogeneous sheet, crustal thickening and strain rates are largest in southern Tibet at the beginning of continentcontinent collision, and increase northward with time [England and Houseman, 1986; England and Searle, 1986]. Thus in both frameworks deformation resulting from the India-Asia continental collision begins first in southern Tibet and later progresses northward, either in steps [e.g., Tapponnier et al., 2001] or smoothly [e.g., England and Houseman, 1986; England and Searle, 1986].

[4] Dates of deformation in northern Tibet, on the other hand, suggest that deformation began there shortly after collision and continued to present-day (Figure 1). Slip along the Altyn Tagh fault has occurred since at least Oligocene time [Yue et al., 2005; Ritts et al., 2004], possibly initiating as early as $\sim 49 \mathrm{Ma}$ [Yin et al., 2002]. Strike slip faults in the Alxa region (Figure 1) show an estimated $70 \mathrm{~km}$ of postCretaceous, pre-mid-Miocene slip [Darby et al., 2005]. Sediment deposition in three basins in north central Tibet does appear to progress northward, but began shortly after collision; deposition took place in Hoh Xil at $\sim 49-23$ Ma, in Qaidam at $\sim 46-2.5 \mathrm{Ma}$, and in Jiuquan from $\sim 29.5 \mathrm{Ma}$ to present [Zhu et al., 2006]. The Zorkol, Subei, and Aksay Basins record deformation since $\sim 30$ Ma [Ritts et al., 2004]. Recently, Yin et al. [2007, 2008a, 2008b] and Zhou et al. [2006] argued that deformation within and adjacent to the Qaidam Basin began in Eocene time. Further east, sedimentation began in Guide Basin in Oligocene time, and active thrust faulting accelerated in the Miocene [Fang et al., 2005]. Increased sedimentation rates occur in Xining Basin for about $5 \mathrm{Myr}$ from $\sim 35$ to $30 \mathrm{Ma}$ [Dai et al., 2006], in the broad-scale Xining-Minhe Basin at $~ 40-$ $30 \mathrm{Ma}$ [Horton et al., 2004], and in the eastern Qaidam Basin near $\sim 14.7,8.1$, and 3.6 Ma [Fang et al., 2007]. Sedimentation in Linxia Basin began before $29 \mathrm{Ma}$ [Fang et al., 2003], and exhumation of adjacent high terrain may have accelerated at $\sim 14$ Ma [Garzione et al., 2005]. Sediment accumulated steadily in the Sikouzi Basin since at least $\sim 20 \mathrm{Ma}$ [Jiang et al., 2007]. Regional clockwise rotation in northeast Tibet occurred in the late Paleogene 

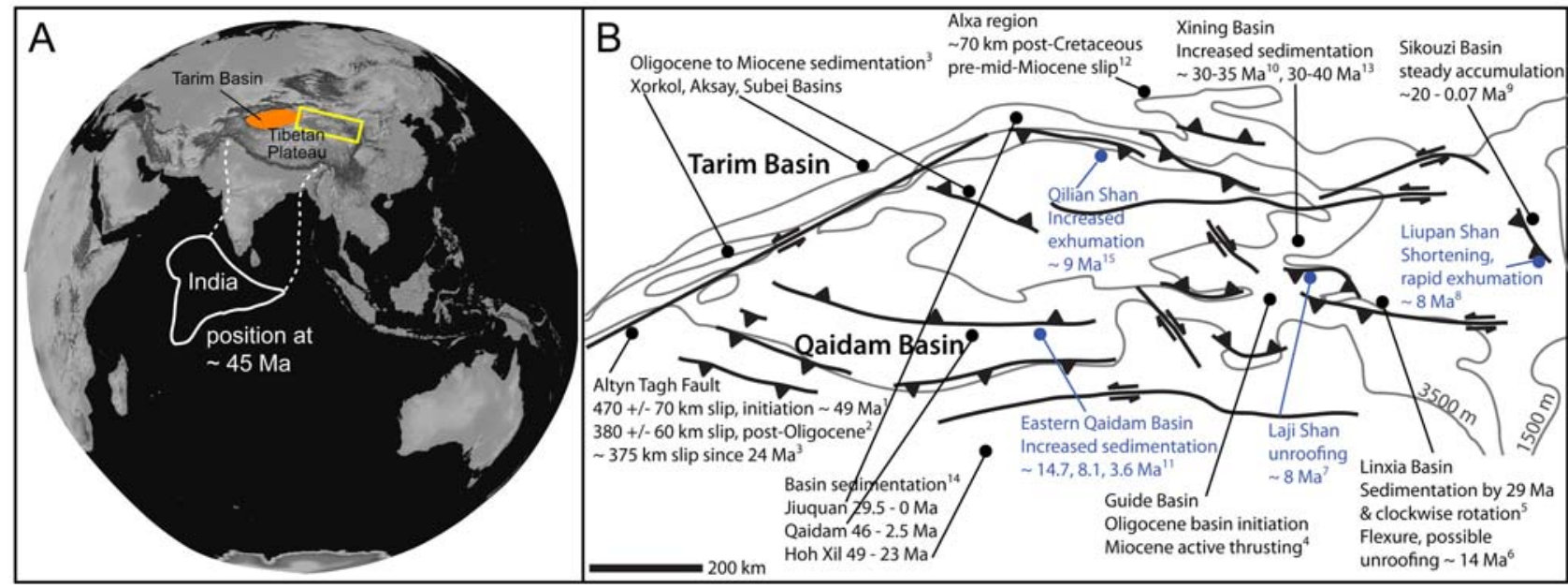

Figure 1. (a) Position of the Indian plate (white outline) relative to northeastern Tibet (yellow box) and Tarim Basin ("strong region") at approximate time of collision ( $45 \mathrm{Ma})$ [Molnar and Stock, 2009]. (b) Principal Cenozoic faults in northeastern Tibet with timing of inferred fault motion from structural, stratigraphic and cooling histories. Grey lines represent generalized 1500, 2500, and $3500 \mathrm{~m}$ elevation contours. Labeled points show locations of geologic data that are interpreted to indicate deformation. Labels in blue represent later deformation (post $\sim 10 \mathrm{Ma}$ ) that may signal surface uplift. References are 1, Yin et al. [2002]; 2, Yue et al. [2005]; 3, Ritts et al. [2004]; 4, Fang et al. [2005]; 5, Fang et al. [2003]; 6, Garzione et al. [2005]; 7, Lease et al. [2007]; 8, Zheng et al. [2006]; 9, Jiang et al. [2007]; 10, Dai et al. [2006]; 11, Fang et al. [2007]; 12, Darby et al. [2005]; 13, Horton et al. [2004]; 14, Zhu et al. [2006]; 15, Zheng et al. (submitted manuscript, 2009).

[Dupont-Nivet et al., 2004]. Evidence of more recent deformation includes increased exhumation rates at $\sim 9 \mathrm{Ma}$ in the Qilian Shan (D. Zheng et al., Fault initiation, topographic growth and erosion rates of the northern Tibetan Plateau (Qilian Shan), submitted to Geology, 2009), and at $\sim 8 \mathrm{Ma}$ in both the Laji Shan [Lease et al., 2007] and the Liupan Shan (east of the plateau) [Zheng et al., 2006].

[5] Collectively, the timing of fault slip, sedimentation, rotation, and exhumation suggests that deformation of northern Tibet commenced soon after the collision between India and Asia and has continued to the present-day. Increased exhumation rates $\sim 8-9 \mathrm{Ma}$ in several regions, however, suggest a change of some kind at that time. Although not central to the topic here, below we offer two possible explanations for this change. Our calculations below suggest that shear strain rates in northern Tibet should increase soon after continental collision begins, but that crustal thickening (and thus likely related exhumation) accelerates $\sim 20-40$ Myr later depending on calculation parameters and initial conditions. Alternatively, late Cenozoic increased surface elevations might result from some other process such as convective removal of lithosphere beneath Tibet [e.g., England and Houseman, 1989; Molnar et al., 1993].

[6] Using thin viscous sheet calculations, we explore initial and boundary conditions that make widespread deformation likely immediately after the collision. We show that deformation at the northern edge of Tibet soon after collision may be expected given a likely initial geometry of
India relative to northern Tibet, and the presence of relatively strong lithosphere north of Tibet.

\section{Calculations}

[7] Assuming that Asian lithosphere can be treated as a viscous fluid on geologic time scales and that Indian lithosphere is effectively rigid, we calculate deformation appropriate for northern Tibet due to an indenting boundary using thin viscous sheet calculations [e.g., Bird and Piper, 1980; England and McKenzie, 1982; Houseman and England, 1986]. The sheet is incompressible and homogeneous (with the exception of a strong region described below) within a gravity field. Stresses on horizontal planes are ignored, and the other components of stress are vertically averaged. All boundaries of the sheet are rigid except a portion of the southern boundary of length $W$ (Figure 2), which is used to indent the sheet at a speed $v_{c}$. (Note that we use primed symbols (e.g., $\left.L^{\prime}, D_{o}^{\prime}, t^{\prime}\right)$ to denote physical quantities that are rendered dimensionless in the calculations using a distance scale $W$ and a time scale $W / v_{c}$. Unprimed symbols $L, W, D_{o}$, and $v_{c}$ below represent values estimated for the thickness of the lithosphere, the width of India, the distance between India and the Tarim Basin at the time of collision, and the convergence rate between them, respectively.) The force balance and continuity equations are solved iteratively, and the vertically averaged deviatoric stress $\bar{\tau}_{i j}$ is related to the strain rate $\dot{\varepsilon}_{i j}$ by a constitutive relationship:

$$
\bar{\tau}_{i j}=B \dot{E}^{(1 / n)-1} \dot{\varepsilon}_{i j}
$$



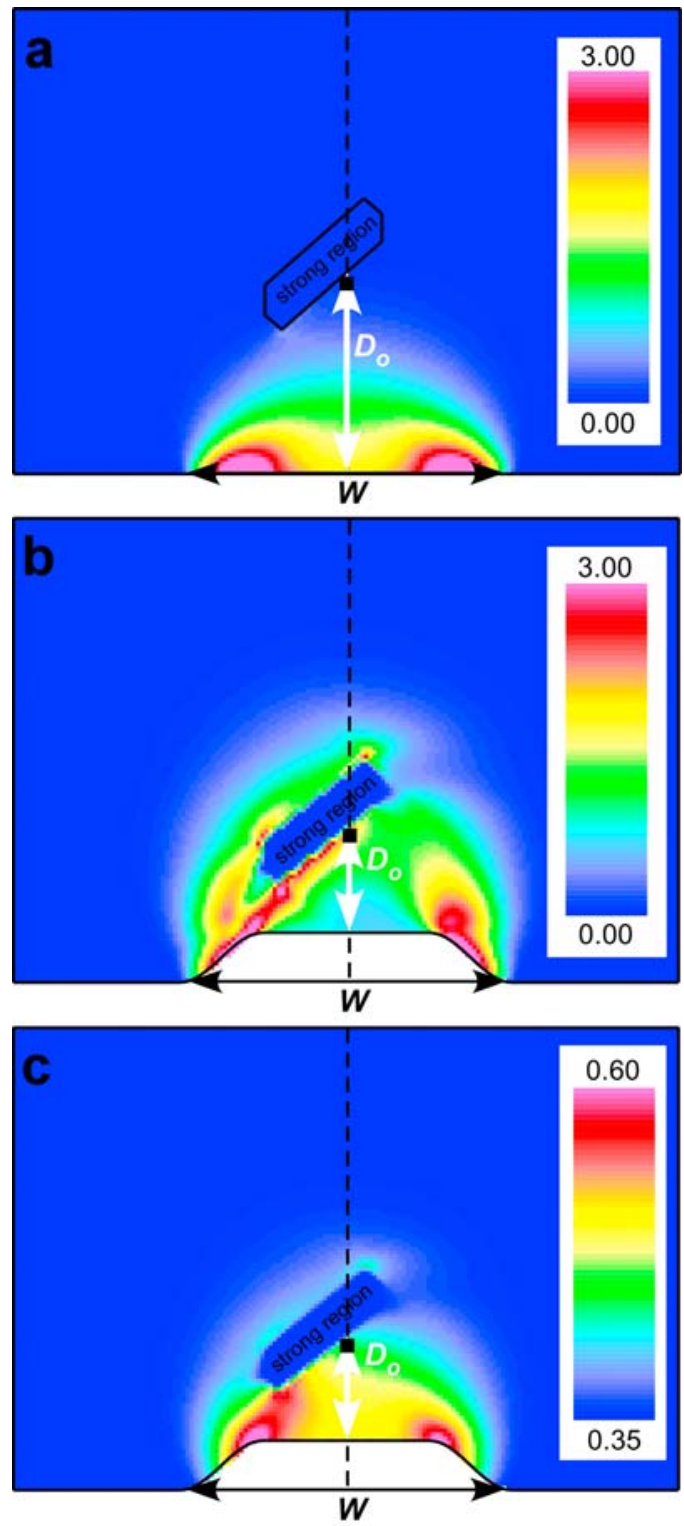

Figure 2. Maps of calculation space showing (a) initial maximum shear strain rate in units $v_{c} / W$ for calculation using $n=10, A r=6, W=5200 \mathrm{~km}$, no initial thickening, and $D_{o}=3000 \mathrm{~km}$. (b) Initial maximum shear strain rate in units $v_{c} / W$ for calculation using $n=10, A r=6, W=5200 \mathrm{~km}$, preexisting thickening, and $D_{o}=1800 \mathrm{~km}$. (c) Initial sheet thickness in units $L$ for calculation shown in Figure 2 b. Dashed vertical line shows location of profiles drawn in Figures 3 and 4. Initial distance between the indenter and strong region $D_{o}$ is shown by white line. Black square indicates location of time series plots in Figures 5 and 6.

where $\dot{E}$ is the second invariant of the strain rate tensor, $B$ is a material parameter related to the strength of the sheet, and $n$ is a rheological parameter. An olivine rheology is described with $n \sim 3-3.5$, and the rheological effect of including a component of frictional faulting in a thin sheet deformation law may be represented using $n>\sim 6$ [Sonder and England, 1986]. Even greater increases in $n$ may also be explained by low-temperature plasticity dominating the deformation [Dayem et al., 2009].

[8] The sheet initially has uniform thickness, but upon indentation, the distribution of its deformation and crustal thickness that develops depends on the Argand number:

$$
A r=\frac{g \rho_{c}\left(1-\left(\rho_{c} / \rho_{m}\right)\right) L}{B\left(v_{c} / L\right)^{1 / n}}
$$

where $g$ is the gravitational constant, $L$ is the thickness of the sheet, and $\rho_{c}$ and $\rho_{m}$ are the densities of the crust and mantle, respectively [England and McKenzie, 1982]. Ar sets the relative importance of the stresses arising from the buoyancy of a variable thickness crustal layer (numerator, equation (2)) to the viscous stresses required to produce indentation (denominator). Deformation is accommodated more by crustal thickening if $\mathrm{Ar}$ is small, and spreads farther away from the indenting boundary if $A r$ is large.

[9] For the homogeneous sheet, two dimensionless parameters, $n$ and $A r$, and boundary conditions determine the flow field. England and Houseman [1986] suggest that the hypsometry of the Tibetan Plateau can be replicated by values of $n=10$ and $A r=3$ or $n=3$ and $A r=1$. Neil and Houseman [1997] use $n=10$ and $A r=6$ or $n=3$ and $A r=3$ when they include regions of contrasting viscous strength to examine areas of convectively thinned lithosphere beneath Tibet. We test these four combinations of $n$ and $A r$ in our calculations so that the region we consider may be compared to the Tibetan Plateau.

[10] To test the effect of a region of strong lithosphere such as the Tarim Basin [e.g., Molnar and Tapponnier, 1981] or the relatively stable, western portion of the North China Craton [e.g., Li et al., 2006; Wang et al., 2005; Xu et al., 2004; Zhao et al., 1999] on deformation of northern Tibet, we compare two sets of calculations. One uses the homogeneous thin viscous sheet, and the other includes a "strong region" of high viscosity (such that strain rates within it are $\sim 1000$ times smaller than those of the surrounding fluid) that represents strong lithosphere north of the Tibetan Plateau [e.g., England and Houseman, 1985; Neil and Houseman, 1997]. We emphasize that these idealized calculations include only one strong region surrounded by relatively weak fluid. In reality, the lithosphere north of Tibet is likely composed of many regions of varying strength such as the Tien Shan, the Tarim Basin, the North China Craton, and perhaps the smaller Qaidam Basin. Rather than complicating the calculations with additional strong or weak regions, we discuss calculation results from the area south of the strong region and interpret them with the entire northern margin of the plateau in mind.

[11] The temporal development of deformation is also affected by the initial distance between the indenter and the strong region $D_{o}$ (Figure 2 ), and strain rates scale with the convergence rate $v_{c}$. We perform calculations for two precollision geometries chosen to bound the possible relative positions of India and the strong lithosphere of the Tarim and Qaidam Basins, and to allow for the thick 
crust in the southern Tibetan Plateau at the time of continental collision.

[12] In the first case, we use initial conditions that probably underestimate the amount of deformation in northern Tibet. We assume that India converges with stable Asia at a rate of $v_{c}=40 \mathrm{~mm} / \mathrm{yr}$ (a conservative estimate; e.g., Molnar and Stock [2009] estimate $v_{c} \sim 59$ and $83 \mathrm{~mm} / \mathrm{yr}$ for the northeast and northwest corners of India respectively before $\sim 20 \mathrm{Ma}$ and 57 and $44 \mathrm{~mm} / \mathrm{yr}$ between 20 and $10 \mathrm{Ma}$ ) since $50 \mathrm{Ma}$ [e.g., Rowley, 1996, 1998], and that this $2000 \mathrm{~km}$ of convergence is taken up entirely by strain of Tibetan lithosphere. Thus we estimate a maximum initial distance between India and the Tarim Basin of $D_{o} \approx 3000 \mathrm{~km}$ ( $\sim 2000 \mathrm{~km}$ convergence $+\sim 1000 \mathrm{~km}$ present-day separation). The initial distance between the indenter and the strong region in the calculation is scaled such that it represents this geometry (Figure 2a).

[13] In the second set of calculations, we use initial conditions chosen to reflect a perhaps more plausible (if somewhat arbitrary) initial configuration. We assume that about half the convergence between India and Eurasia is taken up by Tibetan lithosphere, so that since $40 \mathrm{Ma}$ southern Tibet has converged with stable Asia at a rate of $v_{c}=20 \mathrm{~mm} / \mathrm{yr}$, as suggested for the present-day by GPS velocities [e.g., Feldl and Bilham, 2006; Zhang et al., 2004]. This yields $800 \mathrm{~km}$ of convergence between southern Tibet and the Tarim Basin to be added to the $\sim 1000 \mathrm{~km}$ present-day distance between India and Tarim. Several studies suggest that the crust of southern Tibet was thickened before the continental collision, presumably in response to convergence between the oceanic lithosphere north of India and Asian continental lithosphere, as occurs in the present-day Andes [e.g., Dürr, 1996; England and Searle, 1986; Kapp et al., 2003; Murphy et al., 1997; Volkmer et al., 2007]. We simulate an initial thickened Tibetan lithosphere by preindenting the sheet so that $D_{o} \sim$ $1800 \mathrm{~km}$, and the crust in southern Tibet is already thickened by $\sim 30$ to $60 \%$ (Figures $2 \mathrm{~b}$ and $2 \mathrm{c}$ ).

[14] Paleomagnetic data suggest that the amount of convergence in Tibet, and thus $D_{o}$, may be even smaller than described above. The amount of convergence between northern Tarim and Lhasa since $60 \mathrm{Ma}$ is reported to be $\sim 500 \mathrm{~km}$ [Cogné et al., 1999, Table 2]. A smaller assumed value for $D_{o}$ in our calculations would lead to the development of higher strain rates and greater crustal thickness in northern Tibet than we describe below.

\section{Early Deformation}

\subsection{Homogeneous Sheet}

[15] The amount of convergence that takes place at the northern margin of the Tibetan Plateau at the time of collision depends on the distance between India and the northern margin and lithospheric properties which, in the thin viscous sheet formulation, are described by $n, A r$, and the viscosity contrast between the strong region and its surrounding fluid. In the case of the homogeneous sheet (without a strong region), instantaneous deformation decays approximately exponentially with distance from the indenting boundary with an e-folding distance:

$$
\lambda=\frac{2 W}{\pi \sqrt{n}}
$$

[England et al., 1985]. Given an initial distance between the collision boundary and the northern margin of Tibet, $D_{o}$ and a constant convergence rate $v_{c}$ for the two initial conditions described above, and setting $W=5200 \mathrm{~km}$ (twice the width of the Himalayan arc on a great circle connecting the eastern and western syntaxes so that in the calculations the syntaxes are represented by the corners of the indenter), we can estimate the convergence rate of northern Tibet relative to Eurasia and the strain rate in northern Tibet at the time of collision, $v_{N T}=v_{c} \exp \left(-D_{o} / \lambda\right)$. For $n=3, v_{N T} \sim 2 \mathrm{~mm} / \mathrm{yr}$ if $D_{o}=3000 \mathrm{~km}$ and $v_{c}=40 \mathrm{~mm} / \mathrm{yr}$, and $v_{N T} \sim 4 \mathrm{~mm} / \mathrm{yr}$ if $D_{o}=1800 \mathrm{~km}$ and $v_{c}=20 \mathrm{~mm} / \mathrm{yr}$. (Note that allowing for convergence rates shortly after collision twice those at present [Molnar and Stock, 2009] would double these values.) Deformation rates in northern Tibet are smaller for $n=10: v_{N T} \sim 0.1 \mathrm{~mm} / \mathrm{yr}$ for $D_{o}=3000 \mathrm{~km}$ and $v_{c}=40 \mathrm{~mm} / \mathrm{yr}$, and $v_{N T} \sim 1 \mathrm{~mm} / \mathrm{yr}$ if $D_{o}=1800 \mathrm{~km}$ and $v_{c}=20 \mathrm{~mm} / \mathrm{yr}$. Thus, the homogeneous thin viscous sheet scaling law predicts a small, if not insignificant, amount of deformation in Northern Tibet at the time of collision.

\subsection{Enhanced Strain Rates With Strong Lithosphere North of Tibet}

[16] Next we consider the effect of the presence of relatively strong lithosphere of the Tarim Basin on deformation of the northern part of Tibet by comparing our thin viscous sheet calculations with and without a strong region. Calculated strain rates and crustal thicknesses depend on values chosen for the stress-strain exponent $n$ and the Argand number $A r$, as well as the initial geometry. We describe the effects of each of these parameters in the sections below.

\subsubsection{Effect of $\boldsymbol{n}$ and $A r$ on Strain Rates and Crustal Thickness}

[17] Both $n$ and $A r$ effect the degree to which deformation is concentrated near boundaries and strength discontinuities [e.g., Bell et al., 1977; Dayem et al., 2009]. Stress and strain rate are related in (1) by the coefficient $B \dot{E}^{(1 / n)-1}$ (twice the effective viscosity). Stress varies only gradually across the calculation space, so that large $n$ implies smaller effective viscosity and higher strain rates that are more concentrated near the indenter (Figures 3 and 4). As the sheet is indented, the front of increased strain rates progresses northward, and strain rates localize along the southern boundary of the strong region. Larger strain rates and crustal thicknesses develop for larger than smaller $n$ (Figures 5 and 6).

[18] Small $A r$ implies large viscous resistance relative to buoyant resistance, which produces large thickening rates near boundaries and discontinuities. Large $A r$ implies greater relative buoyant resistance so that deformation spreads away from boundaries and discontinuities, leading to more diffuse crustal thickening that is less concentrated near boundaries (Figure 4). Large $n$ and small $A r$, therefore, lead 


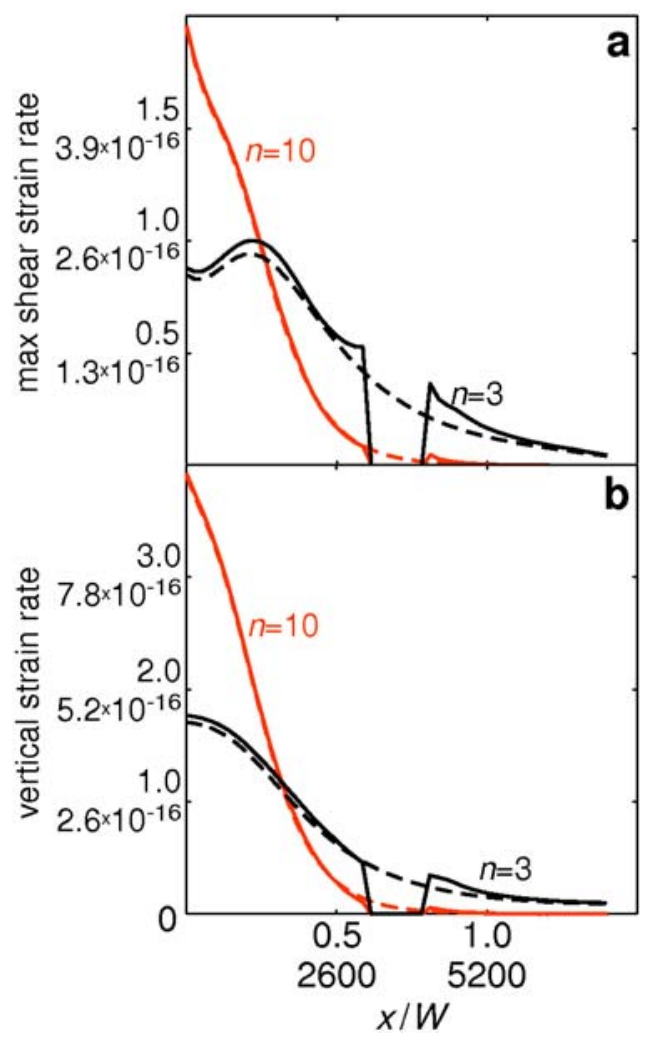

Figure 3. Initial $(\mathrm{t}=0)(\mathrm{a})$ maximum shear strain rate $\left[v_{c} / W\right]$ and (b) vertical strain rate $\left[v_{c} / W\right]$ along a profile from the indenter shown by the dashed line in Figure $2 \mathrm{a}$, for $D_{o}=$ $3000 \mathrm{~km}$. Calculations using $n=3$ shown in black; calculations using $n=10$ shown in red. Solid and dashed lines show values for calculations with and without a strong region, respectively. Axis labels show dimensionless calculation values above scaled dimensional values of distance $[\mathrm{km}]$ and strain rate $[1 / \mathrm{s}]$. Note that crustal thickness is initially uniform across the sheet so that $\mathrm{Ar}$ has no effect on the initial strain rates.

to larger and more localized strain rates and crustal thickening adjacent to the indenting boundary and to the strong region than small $n$ and large $A r$ [e.g., Dayem et al., 2009].

\subsubsection{Initial Strain Rates and Crustal Thickness}

[19] For the calculations scaled to $D_{o}=3000 \mathrm{~km}$ and $v_{c}=$ $40 \mathrm{~mm} / \mathrm{yr}$, the presence of the strong region has a negligible effect on development of horizontal shear and vertical strain across the plateau compared to that for a homogeneous sheet (Figure 3). At the initial time step, the crustal thickness is uniform across the sheet, so that $A r$ has no effect on strain rates. Strain rates are large near the indenter, and decay in a smaller distance from it for larger than smaller $n$.

[20] In contrast, for the calculations with $D_{o}=1800 \mathrm{~km}$, preexisting thickened crust, and $v_{c}=20 \mathrm{~mm} / \mathrm{yr}$, initial shear strain rates are larger across the plateau when the strong region is included (Figures $4 \mathrm{a}$ and $4 \mathrm{~b}$ ). On the northern edge of the plateau, when the strong region is included in the calculation, shear strain rates (Figures $4 c$ and $4 d$ ) are about $40 \%$ larger for $n=3$ and $80 \%$ larger for $n=10$ than those calculated for a homogeneous sheet. In addition, the largest shear strain rates occur just south of the strong region and decrease southward toward the indenter. The Argand number $A r$ has only a small effect on the magnitude of the strain rates adjacent to the strong region. Vertical and shear strain rates from the $n=10$ calculation have similar patterns and magnitudes; the vertical strain rate for the calculation with a strong region is up to $\sim 40 \%$ larger than that without. In the $n=3$ calculation, vertical strain rates are largest near the indenter (Figures $4 \mathrm{c}$ and $4 \mathrm{~d}$ ). Consequently, the crust becomes thicker in northern Tibet when $n=10$ than $n=3$ (Figures $4 \mathrm{e}$ and $4 \mathrm{f}$ ). In both cases crustal thickness is largest near the indenter, and decreases to the north, so that the difference in initial crustal thickness just

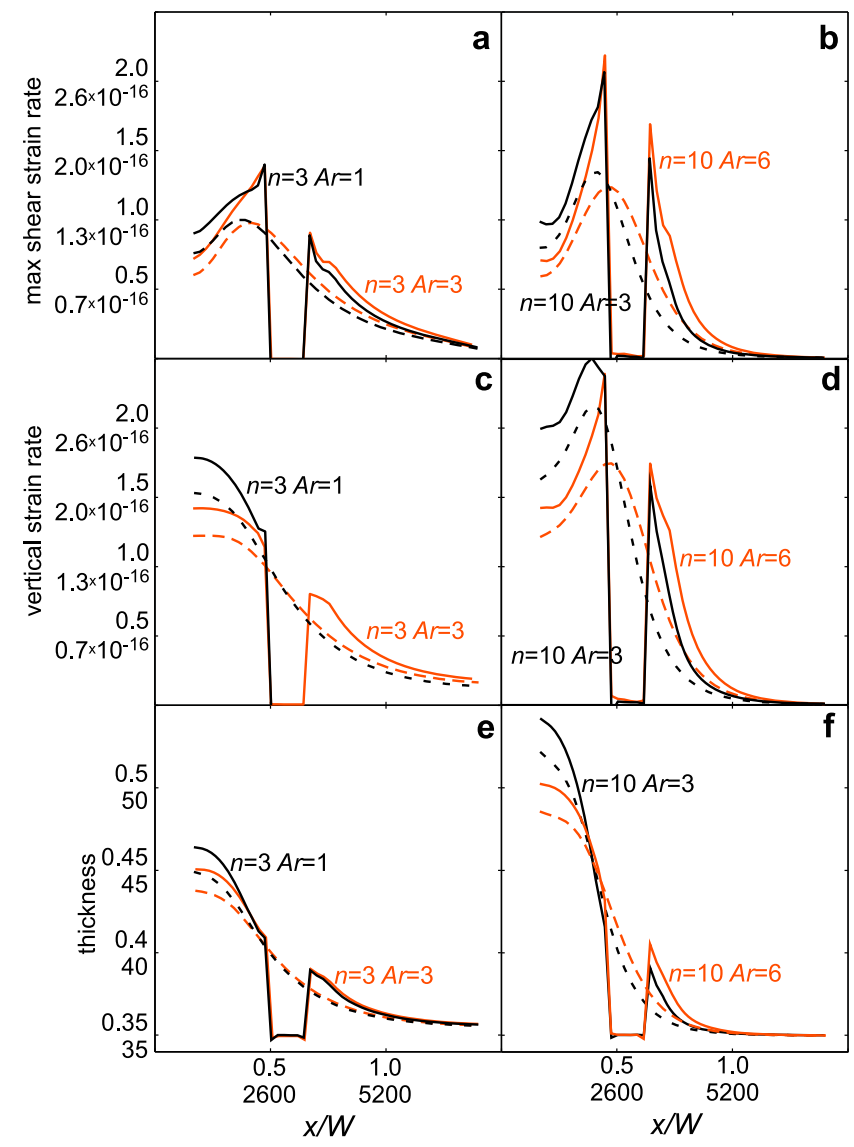

Figure 4. Initial $(\mathrm{t}=0)(\mathrm{a}, \mathrm{b})$ maximum shear strain rate $\left[v_{c} / W\right],(\mathrm{c}, \mathrm{d})$ vertical strain rate $\left[v_{c} / W\right]$, and (e, f) crustal thickness $[L]$ along a profile from the indenter, shown by the dashed line in Figure $2 \mathrm{~b}$, for $D_{o}=1800 \mathrm{~km}$. Figures $4 \mathrm{a}, 4 \mathrm{c}$, and $4 \mathrm{e}$ show $n=3$ calculations, and Figures $4 \mathrm{~b}, 4 \mathrm{~d}$, and $4 \mathrm{f}$ show $n=10$ calculations. Calculations using $n=3, A r=1$ and $n=10, A r=3$ are shown in black; calculations using $n=3$, $A r=3$ and $n=10, A r=6$ are shown in red. Solid and dashed lines show values for calculations with and without a strong region, respectively. Axis labels show dimensionless calculation values above scaled dimensional values of distance $[\mathrm{km}]$, strain rate $[1 / \mathrm{s}]$, and crustal thickness $[\mathrm{km}]$. 


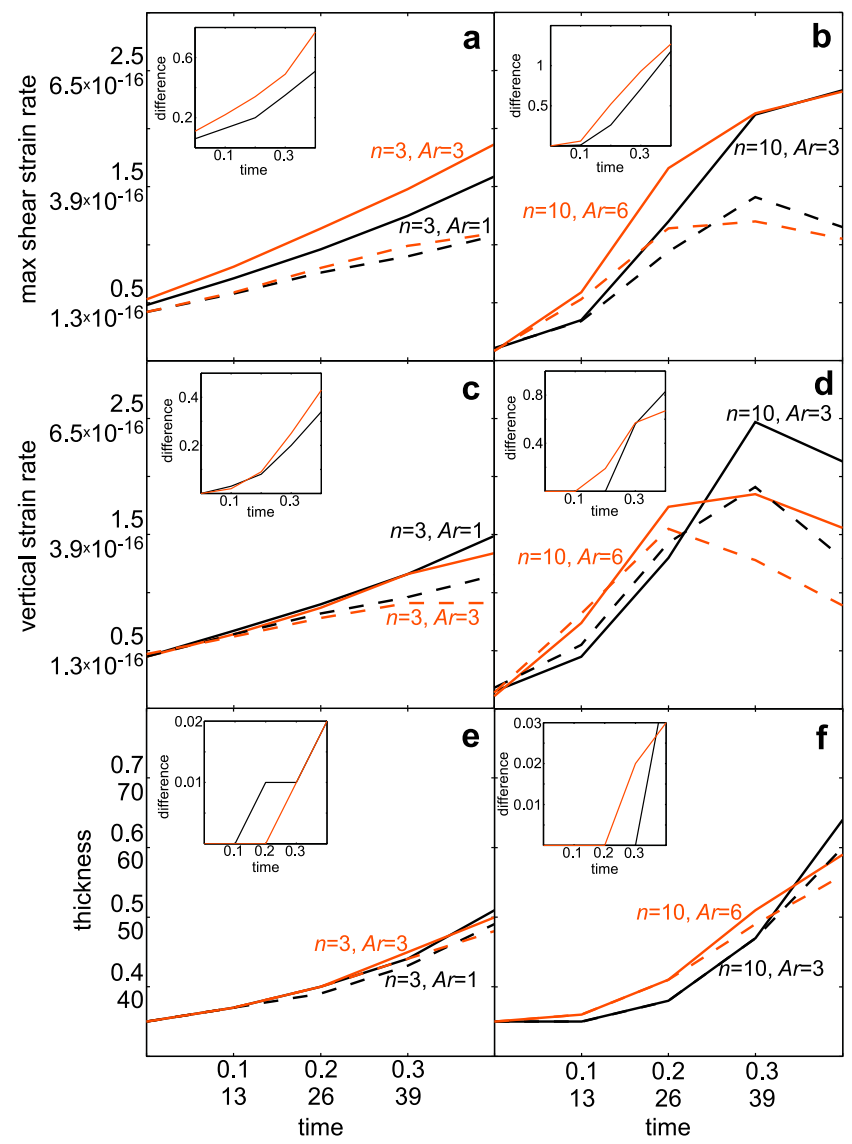

Figure 5. Evolution in time $\left[W / v_{c}\right]$ of $(\mathrm{a}, \mathrm{b})$ maximum shear strain rate $\left[v_{c} / W\right],(\mathrm{c}, \mathrm{d})$ vertical strain rate $\left[v_{c} / W\right]$, and $(\mathrm{e}, \mathrm{f})$ crustal thickness $[L]$ for the point south of the strong region shown in Figure 2, for $D_{o}=3000 \mathrm{~km}$ and $v_{c}=40 \mathrm{~mm} / \mathrm{yr}$. Figures 5a, 5c, and 5e show $n=3$ calculations, and Figures $5 \mathrm{~b}, 5 \mathrm{~d}$, and $5 \mathrm{f}$ show $n=10$ calculations. Calculations using $n=3, A r=1$ and $n=10, A r=3$ are shown in black; calculations using $n=3, A r=3$ and $n=10, A r=6$ are shown in red. Solid and dashed lines show values for calculations with and without a strong region, respectively. Inset shows difference between calculations with and without a strong region. Axis labels show dimensionless calculation values above scaled dimensional values of time [Myr], strain rate $[1 / \mathrm{s}]$, and crustal thickness $[\mathrm{km}]$.

south of the strong region between the calculations with and without the strong region is negligible. In summary, during the early stages of the calculations, the presence of the strong region increases shear and vertical strain rates, and to a lesser degree, crustal thickness if $D_{o}$ is small enough, but has little effect on strain rates and crustal thickness on the northern portion of the plateau if $D_{o}$ is large.

\section{Migration of Strain Rates and Crustal Thickening}

[21] We examine the evolution of strain rates and crustal thickness at a point just south of the strong region (see
Figure 2 for point location). In each calculation, as the sheet is indented, the front of maximum shear and vertical strain rate migrates northward, and is followed by the front of maximum thickness. For the $D_{o}=3000 \mathrm{~km}, v_{c}=40 \mathrm{~mm} / \mathrm{yr}$ calculations, although initially the strain rates for the $n=3$ calculation are larger than those for the $n=10$ calculation, those for the $n=10$ calculation become the larger later in the calculations (Figures $5 \mathrm{a}-5 \mathrm{~d}$ ). In both cases, the strain rates are larger in the calculation with the strong region than without, and the difference between the two generally increases with time (Figures $5 \mathrm{a}-5 \mathrm{~d}$, inset). Larger vertical strain rates and crustal thickness develop in calculations

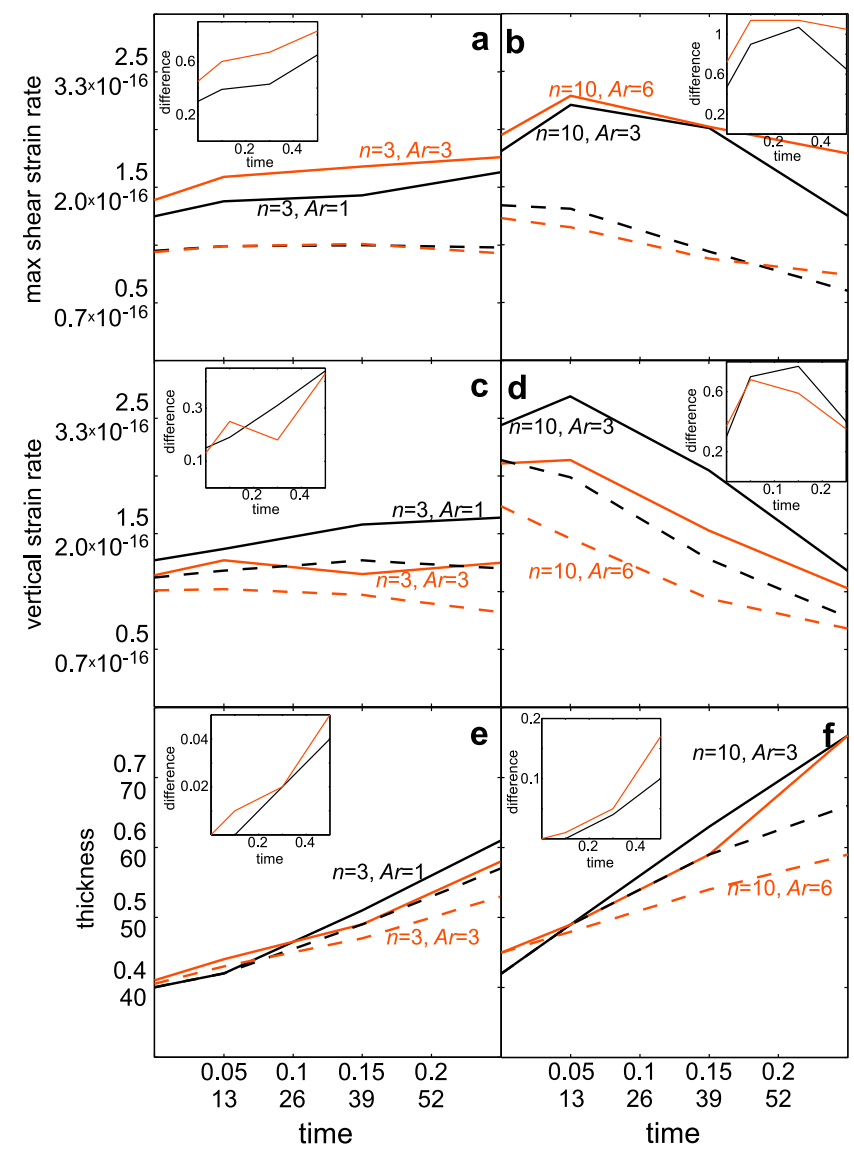

Figure 6. Evolution in time $\left[W / v_{c}\right]$ of $(\mathrm{a}, \mathrm{b})$ maximum shear strain rate $\left[v_{c} / W\right],(\mathrm{c}, \mathrm{d})$ vertical strain rate $\left[v_{c} / W\right]$, and $(\mathrm{e}, \mathrm{f})$ crustal thickness $[L]$ for the point south of the strong region shown in Figure 2, for $D_{o}=1800 \mathrm{~km}$ and $v_{c}=$ $20 \mathrm{~mm} / \mathrm{yr}$. Figures $6 \mathrm{a}, 6 \mathrm{c}$, and $6 \mathrm{e}$ show $n=3$ calculations, and Figures 6b, 6d, and 6f show $n=10$ calculations. Calculations using $n=3, A r=1$ and $n=10, A r=3$ are shown in black; calculations using $n=3, A r=3$ and $n=10$, $A r=6$ are shown in red. Solid and dashed lines show values for calculations with and without a strong region, respectively. Inset shows difference between calculations with and without a strong region. Axis labels show dimensionless calculation values above scaled dimensional values of time [Myr], strain rate [1/s], and crustal thickness $[\mathrm{km}]$. 
with smaller $A r$ (black lines in Figure 5), whereas larger shear strain rates develop in calculations with larger $A r$ (red lines in Figure 5).

[22] Crustal thickness also increases over the course of the calculation; as the time integral of the vertical strain rate, this increase develops more slowly than do increases in strain rates (Figures 5e and 5f). By the end of the calculation $\left(t^{\prime}=0.4\right.$, scaled to $\sim 52 \mathrm{Ma}$ ) the crustal thickness increases by $\sim 70-80 \%$ for $n=10$ and by $\sim 40-45 \%$ for $n=3$, for the values of $\mathrm{Ar}$ considered. Eventually, strain localization due to the presence of the strong region results in crust thicker by only $\sim 4-5 \%$ than that for a homogeneous sheet (Figures 5e and 5f, inset).

[23] If instead we assume that $D_{o}=1800 \mathrm{~km}, v_{c}=$ $20 \mathrm{~mm} / \mathrm{yr}$, and that the crust of southern Tibet was already thick at the time of collision, then not only do greater shear and vertical strain rates occur at the time of collision than for an initially uniform southern Tibet crust, but also more crustal thickening occurs as the calculation progresses (compare Figures 5 and 6, noting that dimensionless time in Figure 6 scales to twice the dimensional time as that in Figure 5 because the convergence rate in Figure 6 is half that in Figure 5). Moreover, a strong region enhances both effects (Figure 6). Because thick crust existed at the time of collision in this case, significantly greater strain rates and thickening occur in the calculations with a strong region compared to those without. Shear strain rates in the calculations with a strong region are approximately $30 \%$ greater than in those without a strong region (Figures $6 \mathrm{a}$ and $6 \mathrm{~b}$, inset). Thickened crust still takes time to develop, but it develops earlier than for the other geometry, and including the strong region leads to an increase in crustal thickness by $\sim 10$ and $30 \%$ for $n=3$ and $n=10$, respectively (Figures $6 \mathrm{e}$ and $6 \mathrm{f}$, inset).

\section{Discussion}

[24] Our calculations suggest that if the Asian lithosphere can be approximated as a thin viscous sheet with a region of high viscosity representing strong lithosphere north of Tibet, then deformation should begin in northern Tibet soon after continental collision begins. More deformation takes place there if the initial distance between northern Tibet and India is shorter, and if the crust of southern Tibet is already thick. As the collision continues, strain rates and crustal thickness increase at the northern margin of Tibet. Crustal thickness, which represents accumulated vertical strain, increases throughout the calculations. Shear and vertical strain rates reach maximum values and then decrease in the latter stages of the calculations as the front of maximum strain rate migrates north of the strong region. We do not attempt to interpret this behavior in the context of deformation north of the plateau because we have not included additional strong regions, for instance, to represent the North China Craton. Had we included a second strong region in our calculations to mimic this craton north of Tibet, we expect that even higher strain rates would be obtained in northern Tibet.

[25] The observation that increased crustal thickness lags the front of maximum horizontal strain rate (Figure 5) may explain the late Miocene rise of mountain ranges on the margins of Tibet that has been inferred from increased exhumation rates at that time [e.g., Lease et al., 2007; Zheng et al., 2006, submitted manuscript, 2009]. Our calculations suggest that rates of crustal thickening can continue to increase after shear and vertical strain rates have begun to decrease (Figure 6). (Note that this is physically possible: the rate of crustal thickening is equal to the product of the crustal thickness and the vertical strain rate. Crustal thickness increases as long as vertical strain rate is positive, so that if thickness is large when vertical strain rate begins to decrease, the rate of crustal thickening can still increase.) Increased exhumation rates may reflect the arrival of the front of rapid thickening. In the calculation more favorable for producing thick crust $\left(D_{o}=1800 \mathrm{~km}\right.$, $v_{c}=20 \mathrm{~mm} / \mathrm{yr}$, an initially thick southern Tibetan crust, $n=$ 10, and $A r=6$ ), crustal thickness on the northern margin of the plateau increases by more than $100 \%$ over $\sim 50$ Ma of collision, which would scale to a surface elevation $\sim 6 \mathrm{~km}$ assuming that the thickened crust is isostatically compensated and no erosion occurred. This estimate is larger than the present-day elevation $\sim 4 \mathrm{~km}$ but, considering that the initial conditions of the calculations are somewhat arbitrary and the uncertainty in the degree to which the mantle lithosphere in this region is isostatically compensated, we find the estimate to be within reason. For the calculation using $n=3$ and $A r=3$, the calculated surface elevation near the northern plateau margin is $\sim 3.5 \mathrm{~km}$ after $\sim 50 \mathrm{Ma}$ of convergence.

[26] The amounts of strain and of crustal thickening at the northern margin of the plateau are also affected by $n$ and, to a lesser degree, $A r$. Once strain and crustal thickness have begun to develop south of the strong region, greater strain rates and thicknesses occur near this boundary for larger $n$ or smaller $A r$, as shown in calculations by Dayem et al. [2009]. They suggest that shear strain rates just south of the Tarim Basin localize in a zone whose width is comparable to that of the Altyn Tagh Fault if $n \sim 10$ and $A r \approx 3-6$. Our results show that if southern Tibetan crust was thick before continental collision began, larger strain rates occur at the northern boundary of Tibet at the time of collision, and surface elevations after $50 \mathrm{Myr}$ of convergence are within range of present-day observations. These findings lead us to agree that $n \sim 10$ better describes strain accommodation in northern Tibet than $n=3$, which suggests that the lithosphere here deforms plastically [e.g., Dayem et al., 2009].

[27] Alternatively, if India was initially farther south of northern Tibet (greater $D_{o}$ ), the crust of southern Tibet was not initially thick, and if $n<\sim 10$, then calculated crustal thicknesses and inferred surface elevations are not sufficiently large to explain modern elevations of northern Tibet. For example, in the $D_{o}=3000 \mathrm{~km}$ calculations, the surface elevation after $\sim 50$ Ma of convergence is $\sim 2 \mathrm{~km}$ for $n=3$. In this case, another process must occur to elevate the surface of northern Tibet by $2 \mathrm{~km}$ or more. In one possible process, thickened and unstable northern Tibetan lithosphere could lead to convective removal of the base of the lithosphere [e.g., England and Houseman, 1989; Molnar and Houseman, 2004; Molnar et al., 1993]. If this process occurred, increased surface elevation (of $\sim 1-2 \mathrm{~km}$ ) would 
result from isostatic compensation of the thinned lithosphere, resulting in a surface elevation $\sim 3-4 \mathrm{~km}$.

\section{Conclusions}

[28] Previous work suggesting that the Tibetan lithosphere progressively accommodates strain from south to north as India collides with Asia [e.g., England and Houseman, 1986; England and Searle, 1986; Tapponnier et al., 2001] disagrees with geologic dates of deformation in northern Tibet. These data suggest that deformation there began soon after $\sim 50 \mathrm{Ma}$, when the collision started (Figure 1). We show that with certain boundary and initial conditions, thin viscous sheet calculations can yield significant strain rates in the northern part of Tibet soon after continental convergence commences, with further thickening of northern Tibetan crust later in the calculations.

[29] Greater amounts of strain and crustal thickening develop in calculations that use larger $n$ in the constitutive relationship (1), smaller $A r$ defined by (2), and a smaller initial distance $D_{o}$ between northern Tibet and northern India at the time of collision. A strong region analogous to the Tarim Basin or other relatively strong cratonic lithosphere north of the Tibetan Plateau leads to enhanced strain rates and crustal thickening south of the strong region. Preexisting thickened crust in southern Tibet also leads to greater strain rates and thickening in northern Tibet. These results suggest that deformation in northern Tibet could take place throughout the time of continental convergence, and that thickening in the later stages of convergence may explain increased exhumation rates on the margins of the plateau at $\sim 10-8 \mathrm{Ma}$.

[30] Acknowledgments. We thank two anonymous referees for constructive criticism. This work was funded by the U.S. National Science Foundation under grant EAR-0507431.

\section{References}

Avouac, J.-P., and P. Tapponnier (1993), Kinematic model of active deformation in central Asia, Geophys. Res. Lett., 20, 895-898, doi:10.1029/93GL00128.

Bell, M. L., S. T. Crough, and A. Nur (1977), NonNewtonian antiplane flow and its application to plate deformation, Tectonophysics, 39, 501-514, doi:10.1016/0040-1951(77)90150-0.

Bird, P., and K. Piper (1980), Plane stress finite element models of tectonic flow in southern California, Phys. Earth Planet. Inter., 21, 158-175, doi:10.1016/ 0031-9201(80)90067-9.

Clark, M. K., and L. H. Royden (2000), Topographic ooze: Building the eastern margin of Tibet by lower crustal flow, Geology, 28, 703-706, doi:10.1130/ 0091-7613(2000)28<703:TOBTEM >2.0.CO; 2 .

Cogné, J. P., N. Halim, Y. Chen, and V. Courtillot (1999), Resolving the problem of shallow magnetizations of Tertiary age in Asia: Insights from paleomagnetic data from the Qiangtang, Kunlun, and Qaidam blocks (Tibet, China), and a new hypothesis, J. Geophys. Res., 104, 17,715-17,734, doi:10.1029/ 1999JB900153.

Dai, S., X. Fang, G. Dupont-Nivet, C. Song, J. Gao, W. Krijgsman, C. Langereis, and W. Zhang (2006), Magnetostratigraphy of Cenozoic sediments from the Xining Basin: Tectonic implications for the northeastern Tibetan Plateau, J. Geophys. Res., 111, B11102, doi:10.1029/2005JB004187.

Darby, B. J., B. D. Ritts, Y. Yue, and Q. Meng (2005), Did the Altyn Tagh fault extend beyond the Tibetan Plateau?, Earth Planet. Sci. Lett., 240, 425-435, doi:10.1016/j.eps1.2005.09.011.

Dayem, K. E., G. A. Houseman, and P. Molnar (2009), Localization of shear along a lithospheric strength discontinuity: Application of a continuous deformation model to the boundary between Tibet and the Tarim Basin, Tectonics, 28, TC3002, doi:10.1029/ 2008 TC002264.

Dupont-Nivet, G., B. K. Horton, R. F. Butler, J. Wang, J. Zhou, and G. L. Waanders (2004), Paleogene clockwise tectonic rotation of the Xining-Lanzhou region, northeastern Tibetan Plateau, J. Geophys. Res., 109, B04401, doi:10.1029/2003JB002620.

Dürr, S. B. (1996), Provenance of Xigaze fore-arc basin clastic rocks (Cretaceous, south Tibet), Geol. Soc. Am. Bull., 108, 669-684, doi:10.1130/00167606(1996)108<0669:POXFAB $>2.3 . \mathrm{CO} ; 2$.
England, P., and G. Houseman (1985), Role of lithospheric strength heterogeneities in the tectonics of Tibet and neighbouring regions, Nature, 315, 297 301, doi:10.1038/315297a0.

England, P., and G. Houseman (1986), Finite strain calculations of continental deformation: 2. Comparison with the India-Asia collision zone, J. Geophys. Res., 91, 3664-3676, doi:10.1029/JB091iB03p03664.

England, P., and G. Houseman (1989), Extension during continental convergence, with application to the Tibetan Plateau, J. Geophys. Res., 94, 17,56117,579, doi:10.1029/JB094iB12p17561.

England, P., and D. McKenzie (1982), A thin viscous sheet model for continental deformation, Geophys. J. R. Astron. Soc., 70, 295-321. (Correction to A thin viscous sheet model for continental deformation, Geophys. J. R. Astron. Soc., 73, 523-532, 1983)

England, P., and M. Searle (1986), The CretaceousTertiary deformation of the Lhasa Block and its implications for crustal thickening in Tibet, Tectonics, 5, 1-14, doi:10.1029/TC005i001p00001.

England, P., G. Houseman, and L. Sonder (1985), Length scales for continental deformation in convergent, divergent, and strike-slip environments: Analytical and approximate solutions for a thin viscous sheet model, J. Geophys. Res., 90, 35513557, doi:10.1029/JB090iB05p03551.

Fang, X., C. Garzione, R. Van der Voo, J. Li, and M. Fan (2003), Flexural subsidence by $29 \mathrm{Ma}$ on the NE edge of Tibet from the magnetostratigraphy of Linxia Basin, China, Earth Planet. Sci. Lett., 210, $545-$ 560, doi:10.1016/S0012-821X(03)00142-0.

Fang, X., M. Yan, R. Van der Voo, D. K. Rea, C. Song, J. M. Parés, J. Gao, J. Nie, and S. Dai (2005), Late Cenozoic deformation and uplift of the NE Tibetan Plateau: Evidence from high-resolution magneto stratigraphy of the Guide Basin, Qinghai Province, China, Geol. Soc. Am. Bull., 117, 1208-1225, doi:10.1130/B25727.1

Fang, X., W. Zhang, Q. Meng, J. Gao, X. Wang, J. King, C. S. Song, S. Dai, and Y. Miao (2007), Highresolution magnetostratigraphy of the Neogene Huaitoutala section in the eastern Qaidam Basin on the NE Tibetan Plateau, Qinghai Province, China and its implication on tectonic uplift of the NE Tibetan Plateau, Earth Planet. Sci. Lett., 258, 293-306, doi:10.1016/j.epsl.2007.03.042.
Feldl, N., and R. Bilham (2006), Great Himalayan earthquakes and the Tibetan Plateau, Nature, 444, 165 - 170, doi:10.1038/nature05199.

Garzanti, E., and T. Van Haver (1988), The Indus clastics: Forearc basin sedimentation in the Ladakh Himalaya (India), Sediment. Geol., 59, 237-249, doi:10.1016/0037-0738(88)90078-4.

Garzione, C. N., M. Ikari, and A. Basu (2005), Source of Oligocene to Pliocene sedimentary rocks in the Linxia basin in NE Tibet from Nd isotopes: Implications for tectonic forcing of climate, Geol. Soc. Am. Bull., 117, 1156-1166, doi:10.1130/B25743.1.

Horton, B. K., G. Dupont-Nivet, J. Zhou, G. L. Waanders, R. F. Butler, and J. Wang (2004), Mesozoic-Cenozoic evolution of the Xining-Minhe and Dangchang basins, northeastern Tibetan Plateau: Magnetostratigraphic and biostratigraphic results, J. Geophys. Res., 109, B04402, doi:10.1029/2003JB002913.

Houseman, G., and P. England (1986), Finite strain calculations of continental deformation: 1 . Method and general results for convergent zones, J. Geophys. Res., 91, 3651-3663, doi:10.1029/JB091iB03p03651.

Jiang, H., Z. Ding, and S. Xiong (2007), Magnetostratigraphy of the Neogene Sikouzi section at Guyuan, Ningxia, China, Palaeogeogr. Palaeoclimatol. Palaeoecol., 243, 223-234, doi:10.1016/j.palaeo. 2006.07.016.

Kapp, P., M. A. Murphy, A. Yin, T. M. Harrison, L. Ding, and J. Guo (2003), Mesozoic and Cenozoic tectonic evolution of the Shiquanhe area of western Tibet, Tectonics, 22(4), 1029, doi:10.1029/2001TC001332.

Lease, R. O., D. W. Burbank, G. E. Gehrels, Z. Wang, and D. Yuan (2007), Signatures of mountain building: Detrital zircon $\mathrm{U} / \mathrm{Pb}$ ages from northeastern Tibet, Geology, 35, 239-242, doi:10.1130/ G23057A.1.

Li, C., R. D. van der Hilst, and M. N. Toksöz (2006), Constraining $P$-wave velocity variations in the upper mantle beneath Southeast Asia, Phys. Earth Planet. Inter., 154, 180-195, doi:10.1016 j.pepi.2005.09.008.

Molnar, P., and G. Houseman (2004), The effects of buoyant crust on the gravitational instability of thickened mantle lithosphere at zones of intracontinental convergence, Geophys. J. Int., 158, 1134-1150, doi:10.1111/j.1365-246X.2004.02312.x.

Molnar, P., and J. M. Stock (2009), Slowing of India's convergence with Eurasia at $\sim 10 \mathrm{Ma}$ and its 
implications for Tibetan mantle dynamics, Tectonics, 28, TC3001, doi:10.1029/2008TC002271.

Molnar, P., and P. Tapponnier (1975), Cenozoic tectonics of Asia: Effects of a continental collision, Science, 189, 419-426, doi:10.1126/science 189.4201.419.

Molnar, P., and P. Tapponnier (1981), A possible dependence of tectonic strength on the age of the crust in Asia, Earth Planet. Sci. Lett., 52, 107-114, doi:10.1016/0012-821X(81)90213-2.

Molnar, P., P. England, and J. Martinod (1993), Mantle dynamics, the uplift of the Tibetan Plateau, and the Indian monsoon, Rev. Geophys., 31, 357-396, doi:10.1029/93RG02030.

Murphy, M. A., A. Yin, T. M. Harrison, S. B. Dürr, Z. Chen, F. J. Ryerson, W. S. F. Kidd, X. Wang, and $X$. Zhou (1997), Did the Indo-Asian collision alone create the Tibetan Plateau?, Geology, 25, 719-722, doi:10.1130/0091-7613(1997)025<0719:DTIACA> 2.3.CO;2.

Neil, E. A., and G. A. Houseman (1997), Geodynamics of the Tarim Basin and the Tian Shan, Tectonics, 16, 571-584, doi:10.1029/97TC01413.

Replumaz, A., and P. Tapponnier (2003), Reconstruction of the deformed collision zone between India and Asia by backward motion of lithospheric blocks, J. Geophys. Res., 108(B6), 2285 , doi:10.1029/2001JB000661.

Ritts, B. D., Y. J. Yue, and S. A. Graham (2004), OligoceneMiocene tectonics and sedimentation along the Altyn Tagh fault, northern Tibetan Plateau: Analysis of the Xorkol, Subei, and Aksay basins, J. Geol., 112, $207-$ 229, doi:10.1086/381658

Rowley, D. B. (1996), Age of initiation of collision between India and Asia: A review of stratigraphic data, Earth Planet. Sci. Lett., 145, 1-13, doi:10.1016/S0012-821X(96)00201-4.

Rowley, D. B. (1998), Minimum age of initiation of collision between India and Asia north of Everest based on the subsidence history of the Zhepure Mountain section, J. Geol., 106, 220-235, doi: $10.1086 / 516018$.

Royden, L. (1996), Coupling and decoupling of crust and mantle in convergent orogens: Implications for strain partitioning in the crust, J. Geophys. Res. 101, 17,679-17,705, doi:10.1029/96JB00951.

Searle, M. P., B. F. Windley, M. P. Coward, D. J. W. Cooper, A. J. Rex, D. Rex, T. Li, X. Xiao, M. Q. Jan, V. C. Thakur, and S. Kumar (1987), The closing Tethys and the tectonics of the Himalaya, Geol. Soc Am. Bull., 98, 678-701, doi:10.1130/0016 7606(1987) $98<678$ :TCOTAT $>2.0$. CO;2.

Sonder, L. J., and P. England (1986), Vertical average of rheology of the continental lithosphere: Relation to thin sheet parameters, Earth Planet. Sci. Lett., 77, 81-90, doi:10.1016/0012-821X(86)90134-2.
Tapponnier, P., and P. Molnar (1976), Slip-line field theory and large-scale continental tectonics, Nature, 264, 319-324, doi:10.1038/264319a0.

Tapponnier, P., G. Peltzer, A. Y. Le Dain, R. Armijo, and P. Cobbold (1982), Propagating extrusion tectonics in Asia: New insights from simple experiments with plasticine, Geology, 10, 611-616, doi:10.1130/ 0091-7613(1982) $10<611:$ PETIAN $>2$. 0.CO;

Tapponnier, P., G. Peltzer, and R. Armijo (1986), On the mechanics of the collision between India an Asia, in Collision Tectonics, edited by M. P. Coward and A. C. Ries, pp. 115-157, Geol. Soc., London.

Tapponnier, P., Z. Xu, F. Roger, B. Meyer, N. Arnaud, G. Wittlinger, and J. Yang (2001), Oblique stepwise rise and growth of the Tibet Plateau, Science, 294, 1671-1677, doi:10.1126/science. 105978 .

Volkmer, J. E., P. Kapp, J. H. Guynn, and Q.-z. Lai (2007), Cretaceous-Tertiary structural evolution of the north central Lhasa terrane, Tibet, Tectonics, 26 , TC6007, doi:10.1029/2005TC001832.

Wang, Y., G. A. Houseman, G. Lin, F. Guo, Y.-J. Wang, W.-M. Fan, and X. Chang (2005), Mesozoic lithospheric deformation in the north China block: Numerical simulation of evolution from orogenic belt to extensional basin system, Tectonophysics, 405, 47-63, doi:10.1016/j.tecto.2005.05.012.

$\mathrm{Xu}$, Y.-G., S.-L. Chung, J. Ma, and L. Shi (2004), Contrasting Cenozoic lithospheric evolution and architecture in the western and eastern Sino-Korean Craton: Constraints from geochemistry of basalts and mantle xenoliths, J. Geol., 112, 593-605, doi: $10.1086 / 422668$

Yin, A., et al. (2002), Tectonic history of the Altyn Tagh fault system in northern Tibet inferred from Cenozoic sedimentation, Geol. Soc. Am. Bull., 114, 1257-1295, doi:10.1130/0016-7606(2002)114<1257:THOTAT> 2.0.CO;2

Yin, A., Y.-Q. Dang, M. Zhang, M. W. McRivette, W. P. Burgess, and X.-H. Chen (2007), Cenozoic tectonic evolution of Qaidam basin and its surrounding regions (part 2), Wedge tectonics in southern Qaidam basin and the eastern Kunlun Range, in Whence the Mountains? Inquiries Into the Evolution of Orogenic Systems: A Volume in Honor of Raymond A. Price, edited by J. W. Sears, T. A Harms, and C. A. Evenchick, Spec. Pap. Geol. Soc Am., 433, 369-390, doi:10.1130/2007.2433(18).

Yin, A., Y.-Q. Dang, L.-C. Wang, W.-M. Jiang, S.-P. Zhou, X.-H. Chen, G. E. Gehrels, and M. W. McRivette (2008a), Cenozoic tectonic evolution of Qaidam basin and its surrounding regions (Part 1), The southern Qilian Shan-Nan Shan thrust belt and northern Qaidam basin, Geol. Soc. Am. Bull., 120, $813-846$, doi:10.1130/B26180.1.
Yin, A., Y.-Q. Dang, M. Zhang, X.-H. Chen, and M. W. McRivette (2008b), Cenozoic tectonic evolution of the Qaidam basin and its surrounding regions (Part 3), Structural geology, sedimentation, and regional tectonic reconstruction, Geol. Soc. Am. Bull., 120, 847-876, doi:10.1130/B26232.1.

Yue, Y., S. A. Graham, B. D. Ritts, and J. L. Wooden (2005), Detrital zircon provenance evidence for large-scale extrusion along the Altyn Tagh fault, Tectonophysics, 406, 165-178, doi:10.1016/ j.tecto.2005.05.023.

Zhang, P.-Z., et al. (2004), Continuous deformation of the Tibetan Plateau from global positioning system data, Geology, 32, 809-812, doi:10.1130/G20554.1.

Zhao, G., S. A. Wilde, P. A. Cawood, and L. Lu (1999), Tectonothermal history of the basement rocks in the western zone of the North China Craton and its tectonic implications, Tectonophysics, 310, 37-53, doi:10.1016/S0040-1951(99)00152-3.

Zheng, D., P.-Z. Zhang, J. Wan, D. Yuan, C. Li, G. Yin, G. Zhang, Z. Wang, W. Min, and J. Chen (2006), Rapid exhumation at $\sim 8 \mathrm{Ma}$ on the Liupan Shan thrust fault from apatite fission-track thermochronology: Implications for growth of the northeastern Tibetan Plateau margin, Earth Planet. Sci. Lett., 248, 198 208, doi:10.1016/j.eps1.2006.05.023.

Zhou, J., F. Xu, T. Wang, A. Cao, and C. Yin (2006), Cenozoic deformation history of the Qaidam Basin, NW China: Results from cross-section restoration and implications for Qinghai-Tibet Plateau tectonics, Earth Planet. Sci. Lett., 243, 195-210, doi:10.1016/j.eps1.2005.11.033.

Zhu, B., W. S. F. Kidd, D. B. Rowley, B. S. Currie, and N. Shafique (2005), Age of initiation of the IndiaAsia collision in the east-central Himalaya, J. Geol., 113, 265-285, doi:10.1086/428805.

Zhu, L., C. Wang, H. Zheng, F. Xiang, H. Yi, and D. Liu (2006), Tectonic and sedimentary evolution of basins in the northeast of Qinghai-Tibet Plateau and their implication for the northward growth of the plateau, Palaeogeogr. Palaeoclimatol. Palaeoecol, 241, 49-60, doi:10.1016/j.palaeo.2006.06.019.

M. K. Clark, Department of Geological Sciences, University of Michigan, 1100 N. University Ave., Ann Arbor, MI 48109, USA. (marinkc@umich.edu)

K. E. Dayem and P. Molnar, Department of Geological Sciences, University of Colorado, Campus Box 399, Boulder, CO 80309, USA. (dayem@colorado. edu; molnar@cires.colorado.edu)

G. A. Houseman, School of Earth and Environment, University of Leeds, Leeds LS2 9JT, UK. (greg@earth. leeds.ac.uk) 